\title{
A review on self-healing coatings for corrosion protection of metals
}

\author{
S. Hari Kumar ${ }^{1 *}$ and S. Karthikeyan ${ }^{2}$ \\ ${ }^{1}$ Chemistry Division, Department of Humanities and Science, Rajalakshmi Institute of \\ Technology, Chennai, Tamilnadu, India \\ ${ }^{2}$ Department of Chemistry, School of Advanced Sciences, VIT University, Vellore, \\ Tamilnadu, India \\ *E-mail: sharikumarphd@gmail.com
}

\begin{abstract}
Corrosion is a natural phenomenon occurring on the surface of metals exposed to different mediums. There have been several methods employed to inhibit such corrosion of metals. Among the existing methods, the use of organic coatings is most popular. However, the main drawback related to the use of organic coatings is their sensitivity towards aggressive mediums, which reduces the coating efficiency. The existing methods are also costly and are not environment friendly. Development of self-healing coatings for corrosion protection of metallic surfaces attracted great interest over the past few years. Self-healing coatings have shown remarkable development and demonstrated great promise in extending the service life, reducing maintenance costs, thereby improving the durability and reliability of conventional protective organic coatings over metallic surfaces. Among the different methods used to improve the selfhealing capabilities in the next generation of organic coatings, loading of corrosion inhibiting agents in the coatings has been widely acknowledged to be the most applicable approach to selfhealing protection. Self-healing coatings showed good corrosion protection of metals in different applications due to controlled release of the active inhibiting agents from the coatings for preventing crack propagation in protective coatings. This review aims to highlight the most recent advances in self-healing coatings loaded with different corrosion inhibitors.
\end{abstract}

Keywords: corrosion, inhibitors, self-healing, coatings.

Received: April 10, 2020. Published: June 26, 2020

doi: $\underline{10.17675 / 2305-6894-2020-9-3-3}$

\section{Introduction}

Corrosion is the metal-environment interaction, which causes changes in the properties of the metal and thereby reduces the efficiency of the metal [1,2]. When the metal is getting deteriorated by the influence of environment, it may become necessary to protect it from the environmental action. Protective coatings are most widely used method to protect metallic surfaces. Decrease of the Gibbs free energy of the system accelerates corrosion. Due to this metal has a strong affinity to return to its original form [3]. This ability of metal to return to its original oxide form is defined as corrosion. Coatings employed for corrosion inhibition must lead to formation of an effective physical barrier, impeding the access of foreign 
materials to the metal surface. The metallic corrosion is the global problem and complicated challenge that has bothered the economy of different countries for many years.

\section{Types of corrosion prevention}

Generally, the corrosion of metal surfaces is protected by coatings through the following mechanisms: corrosion inhibition, electrolytic inhibition, cathodic protection, anodic passivation $[4,5]$. Cathodic protection is carried out by coating with a highly electro-positive metal that polarizes the substrate and behaves as approximate anode. Nevertheless, galvanization of steel substrates by electroplating is regarded as the most ever-present strategy for the protection of metal surfaces. The anodic passivation prevents corrosion by forming a passivating layer on the top of the metal surface that destroys the redox reaction by generating an ion-selective barrier [6,7]. Electrolytic inhibition prevents the corrosion by hindering the migration of ions between cathode and anode. Self-healing coatings also includes introduction of corrosion inhibiting materials within the coating that allow for reformation of organic coatings. Recent advances in metallic coatings have tried to achieve different means of corrosion protection in a single coating for expanded lifetime of the coating against highly corrosive environment $[8,9]$.

\section{Corrosion inhibitors}

Different types of corrosion inhibitors have been developed and used for effective metallic corrosion inhibition. Use of plant extracts in the field of metallic corrosion inhibition is widely growing methods because of their green and environmentally sustainable behavior [10-12]. Various phytochemicals present in the plant extracts leads to strong metal-inhibitor interactions, which develops high inhibition efficiencies of these extracts. These phytochemicals are naturally synthesized by photosynthesis without using any toxic solvents of chemicals that offers them as one of the greenest alternatives to be used for various applications including the field of corrosion inhibition [13]. Chemical medicines or drug molecules are other commonly employed green alternative corrosion inhibitors for metallic corrosion in various electrolytic media [14-17]. Their biological and natural origins offer them as green and environmentally friendly chemicals to be used for several purposes. Generally, drugs are chemically complex molecules those possess several active sites in the form of heteroatoms and extensive conjugation and offer strong bonding with the metallic surface. Extensive uses of inorganic compounds as inhibitors as such or in the combination with organic corrosion inhibitors in solution phase as well as for coating have been reported in literature. Presence of the inorganic compounds (mostly salts) in the solution enhances the effectiveness of the organic corrosion inhibitors through the phenomenon of synergism $[18,19]$. Most of the used synthetic inhibitors are toxic for living organisms and also to the surrounding environment because of their multistep synthesis and use of conversional energy source for heating those are associated with huge discharge of environmental malignant chemicals into the surrounding and reduced yield due to their association with several workups and purification processes [20,21]. In view of this recently organic corrosion 
inhibitors are being synthesized using the one step multicomponent reactions (MCRs) which is generally associated with ease to handle and high yield [22, 23].

\section{Coatings}

Coatings is regarded as a hot topic for protection of metals for many years [24, 25]. Varying the rules that govern human health and environmental problems imposed more limitations on the use of hazardous compounds such as volatile organic compounds and use of chromium(VI) etc. For example, chromium-containing compounds used in coatings are known to be toxic and carcinogenic; the recent regulations impose strong limitations in future use of chromium containing compounds aiming to a great effort in developing chromate-free coatings. New coating techniques were development to overcome the imposed limitations and all technical needs. More investigations on self-healing coatings for corrosion protection of metal surfaces have been carried out. The development of non-toxic coatings and low-volatile organic compounds as potential corrosion inhibitors have been being investigated to develop self-healing coatings.

Due to such limitations and difficulties, more attention was given by scientists to develop new coatings which are self-healing in nature. The main objective of self-healing coating is to incorporate self-healing inhibitors within the coating which lead to partial or full coating recovery from any coating damages. Introduction of urea formaldehyde incorporated with self-healing materials into the organic coating was firstly reported by N. Sottol [26] in the year 1993. Since that, many scientists worked in this hot topic leading to a lot of successful attempts of developing self-healing coatings. The proposed three main mechanisms through which the self-healing properties function are the intrinsic, capsule and vascular strategies.

In intrinsic mechanism, reversible bonding occurs after impairment. Integration of dicyclopentadiene in the matrix can convince such properties but it is highly expensive [27]. In capsule strategy, inhibitors are filled in micro- or nanocapsules and this healing liquid spreading toward the broken area after damage. Many successful attempts have been disclosed on encapsulation technique and were prolonged to multifunctional coatings [28]. For instance, entrapped corrosion inhibitors in the "nano-containers" is working in two steps: a) Curing the destruction produced by the corrosion product. b) Releasing the inhibitor from the nano-container towards the damaged spot for corrosion protection. Investigation in this area has been carried out at several levels and incorporating nanocontainers is regarded as a new break through. The efficiency of $\mathrm{CeO}_{2}$ nanoparticles as corrosion inhibitors in hybrid saline coatings was reported by Montemor [29]. The fabrication of $\mathrm{pH}$ sensitive inhibitors for self-healing corrosion damage is another strategy to protect metal surface. Such strategy was successfully explained by $\mathrm{D}$. Snihirova et al. [30]. They used $\mathrm{CaCO}_{3}$ microbeads saturated with corrosion inhibitors and these beads dissolve at $\mathrm{pH} 4$. This strategy is also valid for $\mathrm{SiO}_{2}$ nanotubes as core inside polymer shell [31] and other inorganic nanoparticles including $\mathrm{TiO}_{2}$ nanoparticles as an example. The major advantage of the nanocontainers is that they can be combined in thin coatings with very low loading capacity [32]. 


\section{Self-healing coatings}

Self-healing is defined as "the ability of a material to heal or repair damages automatically and independently, that is, without any external intervention" [33]. Self-healing materials can be well-known as materials which are capable of autonomously restoring their properties in such a manner that they can function longer as compared to similar materials without selfhealing abilities [34]. Self-healing coatings are required for the total or partial repair of coated areas damaged by ageing or unexpected aggressive events. Concerning self-healing coatings for corrosion protection, two main strategies have been pursued: (i) mending of defects formed in the polymeric coating matrix via addition of polymerizable agents and (ii) inhibition of corroding areas due to the presence of corrosion inhibitors. One of the most common approaches used for controlling releasing of healing agents is Microcapsule Embedment Microencapsulation which is a process of enclosing microparticles of solids, liquids, or gases inside an inert shell, which thereby isolates and protects them from the surrounding environments [35-40]. The outcome of the microencapsulation is called micro-capsules. It contains two components: the core and the shell. Early literature $[41,42]$ recommends the usage of microcapsules of healing agents in a polyester matrix to accomplish a self-healing influence. But they failed in manufacturing applicable self-healing materials. The first applicable investigation of self-healing materials was disclosed in 2001 by White et al. [27]. Self-healing abilities were accomplished by inserting microcapsules of healing agents within polymer layers containing dispersed catalytic materials.

\section{Corrosion inhibitors in coatings}

Environment-friendly surface treatments have been largely investigated for the replacement of chromate in both conversion coatings and primers for painting. Variety of inhibitors producing passivation and precipitation films have been used as inhibitors, such as molybdates, tungstates, phosphates, and silicates, with corrosion inhibition efficiencies similar to those of chromates for the protection of many metals [43-47]. Lanthanide salts were also tested as safe corrosion inhibitors $[48,49]$ and they proved to offer excellent passivation to aluminum, zinc, bronze, steels, stainless and steel alloys [50]. Lanthanide compounds are cathodic inhibitors, which precipitate as trivalent cation hydroxides on cathodic regions due to local alkalinity increase, so hindering the overall corrosion process. $\mathrm{Ce}^{3+}$ salts were also used to produce passive layers based on aluminum and cerium oxideshydroxides $[51,52]$.

Currently, incorporation of corrosion inhibitors into the coatings form self-healing films with improved resistance against corrosion attacks. In some cases, outstanding protective properties are achieved by direct addition of the inhibitors into the polymeric matrix [53,54], but in some cases the inhibitor molecular structure is not compatible with the polymeric matrix and may initiate coating degradation [55]. Therefore, different types of nanocontainers loaded with corrosion inhibitors have been prepared and uniformly dispersed 
into coating formulations to implement a self-healing mechanism. They are supposed to slowly release the active inhibitors in the coating, mainly under diffusion control, helping inhibition of corrosion, in correspondence of coating defects. With this aim, oxide nanoparticles based on inhibiting species (e.g., $\mathrm{CeO}_{2}$, mixed $\mathrm{ZrO}_{2} / \mathrm{CeO}_{2}$ oxides, $\left.\mathrm{Ce}_{2}\left(\mathrm{MoO}_{4}\right)_{3}, \mathrm{CeAlO}_{3}\right)$ also doped with organic inhibitors [56-58], b-cyclodextrin-inhibitor complexes [59, 60], hollow polymeric nanospheres [61], and halloysite tubes [62], have been investigated as promising corrosion inhibitor reservoirs to be incorporated in protective coatings.

In these researches, the inhibitor release from the reservoir is not a selective process under corrosion-induced activation. In fact, it is stimulated not only by the onset of localized corrosion under the coating, where the inhibitor adsorption protects the damaged regions from corrosion propagation and "consumes" dissolved molecule, but also by the continuous leaching of inhibitor molecules into the aggressive solution in contact with the coating.

In a "smart" self-healing coating, entrapped corrosion inhibitors are delivered at the metal/coating interface just where and when corrosion starts. Release of inhibiting ions due to ion exchange phenomena occurs in pigments, such as cerium(III) and calcium(II) cationexchanged bentonites [63] and nanostructured layered double hydroxides (LDHs) [64-66]. Calcium carbonate beads [30] and hydrotalcite microparticles [67] loaded with corrosion inhibitors may provide additional corrosion protection to coatings by releasing the inhibitor molecules in anodic acid regions, where the particle tends to dissolve.

Other smart self-healing coatings enclose nanocontainers of corrosion inhibitors, covered by stratified layers of oppositely charged polyelectrolytes, which can deliver the incorporated corrosion inhibitors in correspondence of coating defects, again released by $\mathrm{pH}$ variations $[68,69]$. In fact, in these oppositely charged polyelectrolyte layers, each layer contains molecules with either weak acid or weak basic ionized functional groups which help forming a stable multilayer film on the inhibitor reservoirs, due to electrostatic interactions. As corrosion starts, $\mathrm{pH}$ variations at anodic and cathodic regions tend to neutralize the salts of weak acids or bases respectively, so determining the opening of the polyelectrolyte shell and the inhibitor release. With this same technique, it is possible to produce smart nano coatings directly applied on the metal surface to be protected by techniques such as layer-by-layer or spraying and entrapping corrosion inhibitors among polyelectrolyte layers [70-72].

Besides $\mathrm{pH}$ variations, IR radiation or visible light, may be devised and implemented to induce controlled inhibitor release. As an example, $\mathrm{TiO}_{2}$ nanoparticles (anatase) modified by nanosized photodeposited silver particles were charged by benzotriazole (BTA), coated by polyelectrolyte films, and incorporated in hybrid zirconia-organosilica coatings. Under irradiation, the production of photoactive species by $\mathrm{TiO}_{2}$ induced oxidation of the polyelectrolyte shell and BTA release [73].

To produce corrosion-inhibitor-containing nanocapsules, Zheludkevich et al. [74] used 70-nm silica nanoparticles to fabricate multilayered nanocapsules in a layer-by-layer manner, with the corrosion inhibitor layer being entrapped between the polyelectrolyte 
multilayers. The polyelectrolyte layer, which not only is sensitive to minor changes in the $\mathrm{pH}$ but also changes its permeability depending on $\mathrm{pH}$ [75], allowed for the controlled release of the entrapped inhibitors through the increased permeability as corrosion causes the $\mathrm{pH}$ near the damaged area to change. The polyelectrolyte multilayers were composed of polyethylene imine (PEI) and polystyrene sulfonate (PSS), while benzotriazole was used as the corrosion inhibitor.

Choi et al. $[76,77]$ also studied the effects of different types of amine-based corrosion inhibitors on the anticorrosive performance of coatings. Both the encapsulation process and the osmotic swelling process were improved when an inhibitor with greater water solubility was used. In particular, linearly structured and highly water-soluble amines exhibited a faster release rate than did the other inhibitors. Recently, 2-mercaptobenzothiazole (MBT) has also attracted significant attention as a corrosion inhibitor when loaded in multilayered nanocapsules because it is a very efficient anticorrosion agent, especially for aluminum alloys.

\section{Conclusion}

Recent studies on self-healing coatings for corrosion protection of metals have been reviewed. Self-healing coatings offers a path for the preparation of smart polymeric coatings with higher efficiency. It can be concluded that the corrosion inhibitor-based self-healing approaches have a wide choice. Releasing loaded inhibitor agents from ruptured nano/MCs or nano/microfibers has been stated as the most applicable method for the development of self-healing materials. Future works in self-healing coatings will focus on reducing the healing time, developing high-yield fabrication, developing hybrid methods of inhibitor incorporation, loading with environmentally friendly inhibitors.

\section{References}

1. K.E. Heusler, D. Landolt and S. Trasaiti, Electrochemical corrosion nomenclature, Pure Appl. Chem., 1989, 61, 19-22. doi: 10.1351/pac198961010019

2. K.R. Trethewey and J. Chamberlain, Corrosion for Students of Science and Engineering, $3^{r d} E d$., John Wiley \& Sons Inc., New York, 1995.

3. B.A. Shaw, R.G. Kelly, What is corrosion?, Electrochem. Soc. Interface, 2006, 15, 24-26.

4. F. Presuel-Moreno, M.A. Jakab, N. Tailleart, M. Goldman and J.R. Scully, Corrosionresistant metallic coatings, Mater. Today, 2008, 11, 14-23. doi: 10.1016/S13697021(08)70203-7

5. A.E. Hughes, I.S. Cole, T.H. Muster and R.J. Varley, Designing green, self-healing coatings for metal protection, NPG Asia Mater., 2010, 2, no. 4, 143-151. doi: 10.1038/asiamat.2010.136

6. B.C. Worley, W.A. Ricks, M.P. Prendergast, B.W. Gregory, R. Collins, J.J. Cassimus and R.G. Thompson, Anodic passivation of tin by alkanethiol self-assembled monolayers examined by cyclic voltammetry and coulometry, Langmuir, 2013, 29, 12969-12981. doi: $10.1021 / 1 \mathrm{a} 402703 \mathrm{w}$ 
7. W.J. Clark, J.D. Ramsey, R.L. McCreery and G.S. Frankel, A galvanic corrosion approach to investigating chromate effect on aluminum alloy 2024-T3, J. Electrochem. Soc., 2002, 149, 179-185. doi: 10.1149/1.1469031

8. R.V. Dennis, V. Patil, J.L. Andrews, J.P. Aldinger, G.D. Yadav and S. Banerjee, Hybrid nanostructured coatings for corrosion protection of base metals: a sustainability perspective, Mater. Res. Express, 2015, 2, no. 3, 032001.

9. A.A. Nazeer and M. Madkour, Potential use of smart coatings for corrosion protection of metals and alloys: A review, J. Mol. Liq., 2018, 253, 11-22. doi: 10.1016/j.molliq.2018.01.027

10. S.K. Sharma, A. Peter and I.B. Obot, Potential of Azadirachta indica as a green corrosion inhibitor against mild steel, aluminum, and tin: a review, J. Anal. Sci. Technol., 2015, 6, 1-16. doi: 10.1186/s40543-015-0067-0

11. P.B. Raja and M.G. Sethuraman, Natural products as corrosion inhibitor for metals in corrosive media-a review, Mater. Lett., 2008, 62, 113-116. doi: $\underline{10.1016 / \text { j.matlet.2007.04.079 }}$

12. M. Abdullah Dar, A review: plant extracts and oils as corrosion inhibitors in aggressive media, Ind. Lubr. Tribol., 2011, 63, 227-233. doi: 10.1108/00368791111140431

13. O.K. Abiola, N. Oforka, E. Ebenso and N. Nwinuka, Eco-friendly corrosion inhibitors: The inhibitive action of Delonix Regia extract for the corrosion of aluminium in acidic media, Anti-Corros. Methods Mater., 2007, 54, 219-224. doi: 10.1108/00035590710762357

14. G. Gece, Drugs: A review of promising novel corrosion inhibitors, Corros. Sci., 2011, 53, 3873-3898. doi: $10.1016 /$ j.corsci.2011.08.006

15. C. Verma, D. Chauhan and M. Quraishi, Drugs as environmentally benign corrosion inhibitors for ferrous and nonferrous materials in acid environment: An overview, $J$. Mater. Environ. Sci., 2017, 8, 4040-4051.

16. S.H. Kumar and S. Karthikeyan, Torsemide and Furosemide as green inhibitors for the corrosion of mild Steel in hydrochloric acid medium, Ind. Eng. Chem. Res., 2013, 52, 7457-7469. doi: 10.1021/ie400815w

17. S.H. Kumar and S. Karthikeyan, 4-chloro-2-((furan-2-ylmethyl)amino) sulfamoylbenzoic acid (FSM) and N-sopropylcarbamoyl)-4-(m-tolylamino) pyridine-3-sulfonamide (TSM) as potential inhibitors for the corrosion of mild steel in Sulphuric acid mediumPart I, Ind. Eng. Chem. Res., 2014, 53, 3415-3425. doi: 10.1021/ie401956y

18. S. Umoren, M. Solomon, I. Udosoro and A. Udoh, Synergistic and antagonistic effects between halide ions and carboxymethyl cellulose for the corrosion inhibition of mild steel in sulphuric acid solution, Cellulose , 2010, 17, 635-648. doi: 10.1007/s10570-0109409-7

19. A.Y. Musa, A.A.H. Kadhum, A.B. Mohamad, M.S. Takriff and E.P. Chee, Inhibition of aluminum corrosion by phthalazinone and synergistic effect of halide ion in $1.0 \mathrm{M} \mathrm{HCl}$, Curr. Appl. Phys., 2012, 12, 325-330. doi: 10.1016/j.cap.2011.07.001 
20. R. Twite and G. Bierwagen, Review of alternatives to chromate for corrosion protection of aluminum aerospace alloys, Prog. Org. Coat., 1998, 33, 91-100. doi: 10.1016/S03009440(98)00015-0

21. S. Weiss, J. Jakobs and T. Reemtsma, Discharge of three benzotriazole corrosion inhibitors with municipal wastewater and improvements by membrane bioreactor treatment and ozonation, Environ. Sci. Technol., 2006, 40, 7193-7199. doi: 10.1021/es061434i

22. C. Verma, L.O. Olasunkanmi, E.E. Ebenso, M. Quraishi and I. Obot, Adsorption behavior of glucosamine-based, pyrimidine-fused heterocycles as green corrosion inhibitors for mild steel: experimental and theoretical studies, J. Phys. Chem. C, 2016, 120, 11598-11611. doi: $10.1021 /$ acs.jpcc.6b04429

23. A. Dandia, S. Gupta, P. Singh and M. Quraishi, Ultrasound-assisted synthesis of pyrazolo $[3,4-b]$ pyridines as potential corrosion inhibitors for mild steel in $1.0 \mathrm{M} \mathrm{HCl}$, ACS Sustainable Chem. Eng., 2013, 1, 1303-1310. doi: 10.1021/sc400155u

24. A.A.O. Magalhaes, B. Tribollet, O.R. Mattos, I.C.P. Margarit and O.E. Barcia, Chromate conversion coatings formation on zinc studied by electrochemical and electrohydrodynamical impedances, J. Electrochem. Soc., 2003, 150, B16-B25. doi: $10.1149 / 1.1528196$

25. J.H. Osborne, Observations on chromate conversion coatings from a sol-gel perspective, Prog. Org. Coat., 2001, 41, 280-286. doi: 10.1016/S0300-9440(01)00143-6

26. C.M. Dry and N. Sottos, Passive smart self-repair in polymer matrix composite materials, Smart Mater. Struct., 1993, 1916, 438-444. doi: $10.1117 / 12.148501$

27. S.R. White, N.R. Sottos, P.H. Geubelle, J.S. Moore, M.R. Kessler, S.R. Sriram, E.N. Brown and S. Viswanatan, Autonomic healing of polymer composites, Nature, 2001, 409, 794-797. doi: 10.1038/35057232

28. R. Araya-Hermosilla, A.A. Broekhuis and F. Picchioni, Reversible polymer networks containing covalent and hydrogen bonding interactions, Eur. Polym. J., 2014, 50, $127-$ 134. doi: $10.1016 /$ j.eurpolymj.2013.10.014

29. M.F. Montemor, R. Pinto and M.G.S. Ferreira, Chemical composition and corrosion protection of silane films modified with $\mathrm{CeO}_{2}$ nanoparticles, Electrochim. Acta, 2009, 54, 5179-5189. doi: 10.1016/j.electacta.2009.01.053

30. D. Snihirova, S.V. Lamaka and M.F. Montemor, "SMART" protective ability of water based epoxy coatings loaded with $\mathrm{CaCO}_{3}$ microbeads impregnated with corrosion inhibitors applied on AA2024 substrates, Electrochim. Acta, 2012, 83, 439-447. doi: 10.1016/j.electacta.2012.07.102

31. F. Micciche, H. Fischer, R. Varley and S. van der Zwaag, Moisture induced crack filling in barrier coatings containing montmorillonite as an expandable phase, Surf. Coat. Technol., 2008, 20, 3346-3353. doi: 10.1016/j.surfcoat.2007.12.003

32. D.G. Shchukin, Container-based multifunctional self-healing polymer coatings, Polym. Chem., 2013, 4, 4871-4877. doi: 10.1039/C3PY00082F 
33. A. Yabuki, Self-Healing Coatings for Corrosion Inhibition of Metals, Mod. Appl. Sci., 2015, 9, no. 7, 214-219. doi: $10.5539 /$ mas.v9n7p214

34. D. Sun, J. An, G. Wu and J. Yang, Double-layered reactive microcapsules with excellent thermal and non-polar solvent resistance for self-healing coatings, J. Mater. Chem. A, 2015, 3, 4435-4444. doi: 10.1039/C4TA05339G

35. V.A. Golovin, A.B. Ilyin, A.D. Aliev, V.A. Shchelkov and V.A. Rabinkov, A study on the desorption of phosphonic acids, corrosion inhibitor precursors, from polymer microcapsules, Int. J. Corros. Scale Inhib., 2018, 7, no. 2, 165-174. doi: 10.17675/23056894-2018-7-2-4

36. V.A. Golovin and S.A. Tyurina, Microencapsulation of corrosion inhibitors and active additives for anticorrosive protective polymer coatings, Int. J. Corros. Scale Inhib., 2019, 8, no. 2, 179-198. doi: 10.17675/2305-6894-2019-8-2-2

37. C. Thies, Microencapsulation, Encycl. Polym. Sci. Eng., John Wiley \& Sons, Inc., New York, 1987, 9, 724-745. doi: 10.1002/0471440264.pst198

38. S. Benita, Microencapsulation: Methods and Industrial Applications, Marcel Dekker, New York, 1996.

39. R. Arshady, Microspheres, Microcapsules and Liposomes, Citrus Books, London, 1999.

40. S.K. Ghosh, Functional Coatings by Polymer Microencapsulation, Wiley-VCH Verlag GmbH, Germany, 2006.

41. C. Dry, Procedures developed for self-repair of polymer matrix composite materials, Compos. Struct., 1996, 35, 263-269. doi: 10.1016/0263-8223(96)00033-5

42. D. Jung, A. Hegeman, N.R. Sottos, P.H. Geubelle and S.R. White, Self-healing composites using embedded microspheres, MD (Am. Soc. Mech. Eng.), 1997, 80, 265275.

43. M.S. Vukasovich and J.P.G. Farr, Molybdate in corrosion inhibition-A review, Mater. Perform., 1986, 9-18.

44. H. Keping, Y. Xiangrong and F. Jingli, A protective coating of silicate on zinc plate, Mater. Corros., 1997, 48, 110-112. doi: 10.1002/maco.19970480206

45. G.D. Wilcox and D.R. Gabe, Passivation studies using group via anions: IV Cathodic redox reactions and film formation, Br. Corros. J., 1984, 19, 196-200. doi: $10.1179 / 000705984798273137$

46. C.R. Clayton and Y.C. Lu, A bipolar model of the passivity of stainless steels-III. The mechanism of $\mathrm{MoO}_{4}^{2-}$ formation and incorporation, Corros. Sci., 1989, 29, 881-898. doi: 10.1016/0010-938X(89)90059-0

47. V.A. Golovin, A.B. Il'in, A.D. Aliev and V.A. Rabinkov, Mass Transfer of PhosphorusContaining Corrosion Inhibitors in Epoxy Protective Coatings, Prot. Met. Phys. Chem. Surf., 2019, 55, 1345-1351. doi: 10.1134/S2070205119070050

48. B.R.W. Hinton, D.R. Arnott and N.E. Ryan, Inhibition of aluminum alloy corrosion by cerous cations, Met. Forum, 1984, 7, no. 4, 211-212.

49. B.R.W. Hinton and L. Wilson, The corrosion inhibition of zinc with cerous chloride, Corros. Sci., 1989, 28, 967-975, 977-985. doi: 10.1016/0010-938X(89)90087-5 
50. M. Bethencourt, F.J. Botana, J.J. Calvino, M. Marcos and M.A. Rodríguez-Chacón, Lanthanide compounds as environmentally-friendly corrosion inhibitors of aluminium alloys: a review, Corros. Sci., 1998, 40, 1803-1819. doi: 10.1016/S0010938X(98)00077-8

51. B.R.W. Hinton, "Corrosion Prevention and Chromates, the End of an Era"-Part 1, Met. Finish., 1991, 89, 55-61.

52. S.V. Oleinik and Yu.I. Kuznetsov, Corrosion inhibitors in conversion coatings. IV, Prot. Met., 2007, 43, 391-397. doi: 10.1134/S0033173207040133

53. M.L. Zheludkevich, R. Serra, M.F. Montemor, K.A. Yasakau, I.M.M. Salvado and M.G.S. Ferreira, Nanostructured sol-gel coatings doped with cerium nitrate as pretreatments for AA2024-T3: Corrosion protection performance, Electrochim. Acta, 2005, 51, 208-217. doi: 10.1016/j.electacta.2005.04.021

54. T.A. Markley, J.I. Mardel, A.E. Hughes, B.R.E. Hinton, A.M. Glenn and M. Forsyth, Chromate replacement in coatings for corrosion protection of aerospace aluminium alloys, Mater. Corros., 2011, 62, 836-840. doi: 10.1002/maco.200905597

55. D. Shchukin, M. Zheludkevich, K. Yasakau, S. Lamaka, M.G.S. Ferreira and H. Möhwald, Layer-by-Layer Assembled Nanocontainers for Self-Healing Corrosion Protection, Adv. Mater., 2006, 18, 1672-1678. doi: 10.1002/adma.200502053

56. I. Kartsonakis, I. Daniilidis and G. Kordas, Encapsulation of the corrosion inhibitor 8hydroxyquinoline into ceria nanocontainers, J. Sol-Gel Sci. Technol., 2008, 48, 24-31. doi: $10.1007 / \mathrm{s} 10971-008-1810-4$

57. I.A. Kartsonakis，E.P. Koumoulos，A.C. Balaskas， G.S. Pappas，C.A. Charitidis and G.C. Kordas, Hybrid organic-inorganic multilayer coatings including nanocontainers for corrosion protection of metal alloys, Corros. Sci., 2012, 57, 56-66. doi: 10.1016/j.corsci.2011.12.034

58. M. Plawecka, D. Snihirova, B. Martins, K. Szczepanowicz, P. Warszynski and M.F. Montemor, Self-healing ability of inhibitor-containing nanocapsules loaded in epoxy coatings applied on aluminium 5083 and galvanneal substrates, Electrochim. Acta, 2014, 140, 282-293. doi: 10.1016/j.electacta.2014.04.035

59. A.N. Khramov, N.N. Voevodin, V.N. Balbyshev and M.S. Donley, Hybrid organoceramic corrosion protection coatings with encapsulated organic corrosion inhibitors, Thin Solid Films, 2004, 447-448, 549-557. doi: $10.1016 /$ j.tsf.2003.07.016

60. A.N. Khramov, V.N. Balbyshev, L.S. Kasten and R.A. Mantz, Sol-gel coatings with phosphonate functionalities for surface modification of magnesium alloys, Thin Solid Films, 2006, 514, 174-181. doi: 10.1016/j.tsf.2006.02.023

61. G.-D. Fu, G.L. Li, K.G. Neoh and E.T. Kang, Hollow polymeric nanostructuresSynthesis, morphology and function, Prog. Polym. Sci., 2011, 36, 127-167. doi: 10.1016/j.progpolymsci.2010.07.011

62. D. Fix, D. Andreeva, Y.M. Lvov, D.G. Shchukin and H. Möhwald, Application of Inhibitor-Loaded Halloysite Nanotubes in Active Anti-Corrosive Coatings, Adv. Funct. Mater., 2009, 19, 1720-1727. doi: 10.1002/adfm.200800946 
63. S. Bohm, H.N. McMurray, S.M. Powell and D.A. Worsley, Novel environment friendly corrosion inhibitor pigments based on naturally occurring clay minerals, Mater. Corros., 2001， 52, 896-903. doi: 10.1002/1521-4176(200112)52:12<896::AIDMACO896>3.0.CO;2-8

64. M.L. Zheludkevich, S.K. Poznyak, L.M. Rodrigues, D. Raps, T. Hack, L.F. Dick, T. Nunes and M.G.S. Ferreira, Active protection coatings with layered double hydroxide nanocontainers of corrosion inhibitor, Corros. Sci., 2010, 52, 602-611. doi: $\underline{\text { 10.1016/j.corsci.2009.10.020 }}$

65. J. Tedim, A. Kuznetsova, A.N. Salak, M.F. Montemor, D. Snihirova, M. Pilz, M.L. Zheludkevich and M.G.S. Ferreira, $\mathrm{Zn}-\mathrm{Al}$ layered double hydroxides as chloride nanotraps in active protective coatings, Corros. Sci., 2012, 55, 1-4. doi: 10.1016/j.corsci.2011.10.003

66. T. Stimpfling, F. Leroux and H. Hintze-Bruening, Unraveling EDTA corrosion inhibition when interleaved into Layered Double Hydroxide epoxy filler system coated onto aluminum AA 2024, Appl. Clay Sci., 2013, 83-84, 32-41. doi: 10.1016/j.clay.2013.08.005

67. D. Snihirova，S.V. Lamaka，M. Taryba，A.M. Salak，S. Kallip， M.L. Zheludkevich, M.G.S. Ferreira and M.F. Montemor, Hydroxyapatite microparticles as feedback-active reservoirs of corrosion inhibitors, ACS Appl. Mater. Interfaces, 2010, 2, 3011-3022. doi: $\underline{10.1021 / a m 1005942}$

68. S.V. Lamaka, D.G. Shchukin, D.V. Andreeva, M.L. Zheludkevich, F. Möhwald and M.G.S. Ferreira, Sol-Gel/Polyelectrolyte Active Corrosion Protection System, Adv. Funct. Mater., 2008, 18, 3137-3147. doi: 10.1002/adfm.200800630

69. M.F. Montemor, Functional and smart coatings for corrosion protection: a review of recent advances, Surf. Coat. Technol., 2014, 258, 17-37. doi: 10.1016/j.surfcoat.2014.06.031

70. N.Y. Abu-Thabit and A.S. Hamdy, Stimuli-responsive polyelectrolyte multilayers for fabrication of self-healing coatings-A review, Surf. Coat. Technol., 2016, 303, 406424. doi: $10.1016 /$ j.surfcoat.2015.11.020

71. D.V. Andreeva, D. Fix, H. Möhwald and D.G. Shchukin, Self-Healing Anticorrosion Coatings Based on $\mathrm{pH}$-Sensitive Polyelectrolyte/Inhibitor Sandwichlike Nanostructures, Adv. Mater., 2008, 20, 2789-2794. doi: 10.1002/adma.200800705

72. P. Lavalle, J.C. Voegel, D. Vautier, B. Senger, P. Schaaf and V. Ball, Dynamic Aspects of Films Prepared by a Sequential Deposition of Species: Perspectives for Smart and Responsive Materials, Adv. Mater., 2011, 23, 1191-1221. doi: 10.1002/adma.201003309

73. E.V. Skorb, A.G. Skirtach, D.V. Sviridov, D.G. Shchukin and H. Möhwald, LaserControllable Coatings for Corrosion Protection, ACS Nano, 2009, 3, 1753-1760. doi: $\underline{10.1021 / \mathrm{nn} 900347 \mathrm{x}}$ 
74. M.L. Zheludkevich, D.G. Shchukin, K.A. Yasakau, H. Möhwald and M.G.S. Ferreira, Anticorrosion coatings with self-healing effect based on nanocontainers impregnated with corrosion inhibitor, Chem. Mater., 2007, 19, 402-411. doi: $10.1021 / \mathrm{cm} 062066 \mathrm{k}$

75. A.A. Antipov and G.B. Sukhorukov, Polyelectrolyte multilayer capsules as vehicles with tunable permeability, Adv. Colloid Interface Sci., 2004, 111, 49-61. doi: 10.1016/j.cis.2004.07.006

76. H. Choi, Y.K. Song, K.Y. Kim and J.M. Park, Encapsulation of triethanolamine as organic corrosion inhibitor into nanoparticles and its active corrosion protection for steel sheets, Surf. Coat. Technol., 2012, 206, 2354-2362. doi: 10.1016/j.surfcoat.2011.10.030

77. H. Choi, K.Y. Kim and J.M. Park, Encapsulation of aliphatic amines into nanoparticles forself-healing corrosion protection of steel sheets, Prog. Org. Coat., 2013, 76, 13161324. doi: $\underline{10.1016 / j . p o r g c o a t .2013 .04 .005}$ 